Original Article

\title{
Assessment of Dietary Practices Among Pregnant Anemic Females
}

Kiran Ashraf ${ }^{1}$, Aiza Talat ${ }^{1}$, Saba Yousaf ${ }^{1}$, Iraj Jamshaid ${ }^{1}$, Farheen Zaidi ${ }^{1}$

${ }^{1}$ University Institute of Diet and Nutritional Sciences, Faculty of Allied Health Sciences, The University of Lahore, Lahore, Pakistan

Keywords: Diet, anemia, pregnancy

\section{How to Cite:}

Ashraf, K., Talat, A., yousaf, S. Jamshaid, I., \& Zaidi, F.

(2020). Assessment of Dietary

Practices Among Pregnant

Anemic Females: Dietary

Practices Among Pregnant

Anemic Females. DIET

FACTOR (Journal of

Nutritional \&Amp; Food

Sciences), 1(01), 7-10.

https://doi.org/10.54393/df.v1i0 1.3

Corresponding author:

Kiran Ashraf

University Institute of Diet and Nutritional Sciences, Faculty of Allied Health Sciences, The University of Lahore, Lahore,

Pakistan

kiranashraf316@gmail.com

\section{Article History}

Received: $19^{\text {th }}$ February 2020

Accepted: 23 ${ }^{\text {rd }}$ March 2020

Published: $30^{\text {th }}$ June 2020

\begin{abstract}
Anemia is interpreted as low blood hemoglobin values. This medical condition can both developed and underdeveloped countries. The ability of blood to transfer oxygen to tissues is affected when the hemoglobin is low, which in turn develops symptoms such as fatigue, compromised physical work capacity, and shortness of breath. Objective: To find out the dietary practices among pregnant females. Methods: It was a comparative cross-sectional study. The substantial data was collected from the gynecology department, vaccination department of Tertiary Care Hospitals, Lahore. Nonprobability convenient sampling criteria were utilized in the study. 150 participants were selected for the study. This sample was finalized based on exclusion and inclusion criteria. Out of 150 pregnant females, 75 anemic pregnant females were placed in the experimental group and 75 non-anemic pregnant females were assigned to the control group. The exclusion criteria suggested that non-pregnant and noncooperative patients will not be included in the study Results: Maximum women belonged to the age group 26-30 years, and the employment status of the women was a housewife. $45 \%$ of women also had craving for pica because of the anemia. $68 \%$ of women were falling in the category of moderate anemia. The malpractices in diet were also inducing iron deficiency like $59 \%$ of women took tea after the meal. It was also interpreted that non-consumption of beef ( $41 \%$ of women), chicken ( $22 \%$ of women), fish ( $58 \%$ of women), and egg ( $34 \%$ of women) were recorded to be more anemic Conclusions: The current study investigated the causative factors of anemia. It was inferred that low socio-economic status and less consumption of ironrich foods make women prone to anemia. Pregnant women are also not cognizant wit ironabsorption inhibiting foods which leads to complications and abnormalities in pregnancy outcomes.
\end{abstract}

\section{INTRODUCTION}

Anemia is interpreted as low blood hemoglobin values [1]. This medical condition can both developed and underdeveloped countries [2]. The ability of blood to transfer oxygen to tissues is affected when the hemoglobin is low, which in turn develops symptoms such as fatigue, compromised physical work capacity, and shortness of breath [3,4]. Three mechanisms mainly lead to anemia: blood loss, when the body is unable to produce enough red blood cells (erythropoiesis), and when red blood cells die (hemolysis) [5].Genetic disorders and deficiency of certain nutrients are other contributors to anemia. The main contributing factor is deficiencies of vitamins A, B2 (riboflavin), B6 (pyridoxine), B12 (cobalamin) [6], C, D, and E, folate, and copper can also lead to anemia [7].

Infants, children under five years, adolescents, females of reproductive age (both pregnant and non-pregnant) and elderly people are more prone to anemia [8]. Women's susceptibly is because of menstruation and pregnancy [9]. Even low hemoglobin levels can result in maternal and perinatal mortality [10]. In newborn children, anemia has likewise been found to cause cognitive and behavioral dysfunction, low iron stores \& iron deficiency anemia [11].

The iron-deficient person can develop Pica in which there are cravings for ingestion of non-food substances [12]. Pica consumption in pregnancy is very common and, if neglected, both mother and fetus may be at risk [13]. 
Rich dietary sources of iron include meat especially offal (organ meat), fish, eggs, poultry, and meat extracts [14]. Whereas bread and flour, breakfast cereals, dark green vegetables, pulses, nuts, dried fruits like prunes, figs, and apricots are good sources of iron. Absorption of iron is promoted by Vitamin $\mathrm{C}$ and is inhibited by the consumption of phytates, tea, coffee, calcium-rich foods [15]. Plant sources like tubers, vegetables, cereals, and pulses contain Non-Haem iron which is of low bio-availability and an essential source of dietary iron in developing countries [16].

$56 \%$ of pregnant women in developing countries suffer from anemia. It is assessed that about 1.3 billion people all over the world suffer anemia, making it a standout amongst the most critical health problems globally [17]. 49\% anemia was found prevalent among women in Pakistan according to The National Nutrition Survey (NNS) of 2011 [18]. The normal range of hemoglobin in women is 11-16 g/dl [19]. There are three categories of anemia mild anemia ranging from 10-10.9 g/dl, moderate anemia $7-10 \mathrm{~g} / \mathrm{dl}$, and severe anemia ranges $<7 \mathrm{~g} / \mathrm{dl}[19]$.

\section{METHODs}

It was a comparative cross-sectional study. The substantial data was collected from the gynecology department, vaccination department of Tertiary Care Hospitals, Lahore. The complete study was conducted in 4 months. Nonprobability convenient sampling criteria were utilized in the study. 150 participants were selected for the study. This sample was finalized based on exclusion and inclusion criteria. Out of 150 pregnant females, 75 anemic pregnant females were placed in the experimental group and 75 non-anemic pregnant females were assigned to the control group. The exclusion criteria suggested that non-pregnant and non-cooperative patients will not be included in the study.

\section{Results}

In this study $10.7 \%$ women were suffering from first-trimester. Whereas $43.3 \%$ and $46 \%$ women were suffering from $2^{\text {nd }}$ and $3^{\text {rd }}$ trimester respectively (Table 1). Table 2 shows that $98.7 \%$ participant were from urban areas and remaining $2 \%$ were from rural areas. Majority of participants was belonged to lower class (40.7\%). About thirty-three percent (32.7\%) women were from middle class and $26.7 \%$ were from upper class as shown in table 3 .

\begin{tabular}{|c|l|c|}
\hline Sr no & Trimester of pregnancy & Frequency $(\%)$ \\
\hline 1. & $1^{\text {st }}$ trimester & $16(10.7)$ \\
\hline 2. & $2^{\text {nd }}$ trimester & $65(43.3)$ \\
\hline 3. & $3^{\text {rd }}$ trimester & $69(46)$ \\
\hline 4. & TOTAL & $150(100)$ \\
\hline
\end{tabular}

Table 1: Frequency distribution of duration of pregnancy

\begin{tabular}{|c|l|c|}
\hline Sr no & Residential Area & Frequency (\%) \\
\hline 1. & Urban & $148(98.7)$ \\
\hline 2. & Rural & $2(1.3)$ \\
\hline 3. & TOTAL & $150(100)$ \\
\hline
\end{tabular}

Table 2: Frequency distribution of the residential location of the patient

\begin{tabular}{|c|l|c|}
\hline Sr no & Socio-economic status & Frequency $\%$ \\
\hline 1. & Lower class & $61(40.7)$ \\
\hline 2. & Middle class & $49(32.7)$ \\
\hline 3. & Upper class & $40(26.7)$ \\
\hline 4. & TOTAL & $150(100)$ \\
\hline
\end{tabular}

Table 3: Frequency distribution of socio-economic status of patients

\section{Frequency distribution of symptoms:}

89 patients felt fatigued whereas 61 patients didn't, 84 patients faced shortness of breath and 66 patients didn't, 84 patients faced nausea and vomiting and 66 patients didn't, 13 patients had spoon-shaped nails and 137 patients didn't. 33 patients suffered joint pain and 117 had no joint pain, 86 patients suffered pain in bones whereas 64 patients had no bones in pain. 


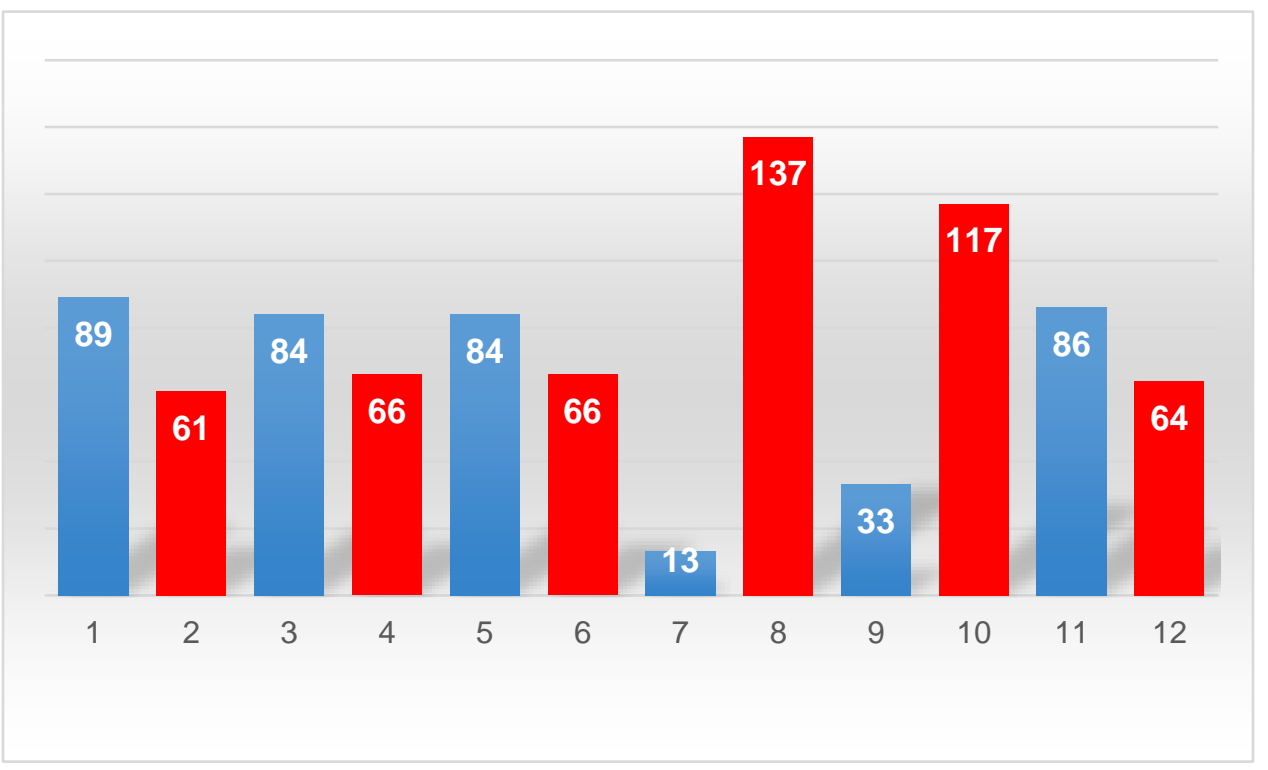

Figure 1: Frequency distribution of symptoms

Frequency distribution of taking an iron supplement:

$78.7 \%$ of patients were taking iron supplements and $21.3 \%$ weren't as shown in the figure

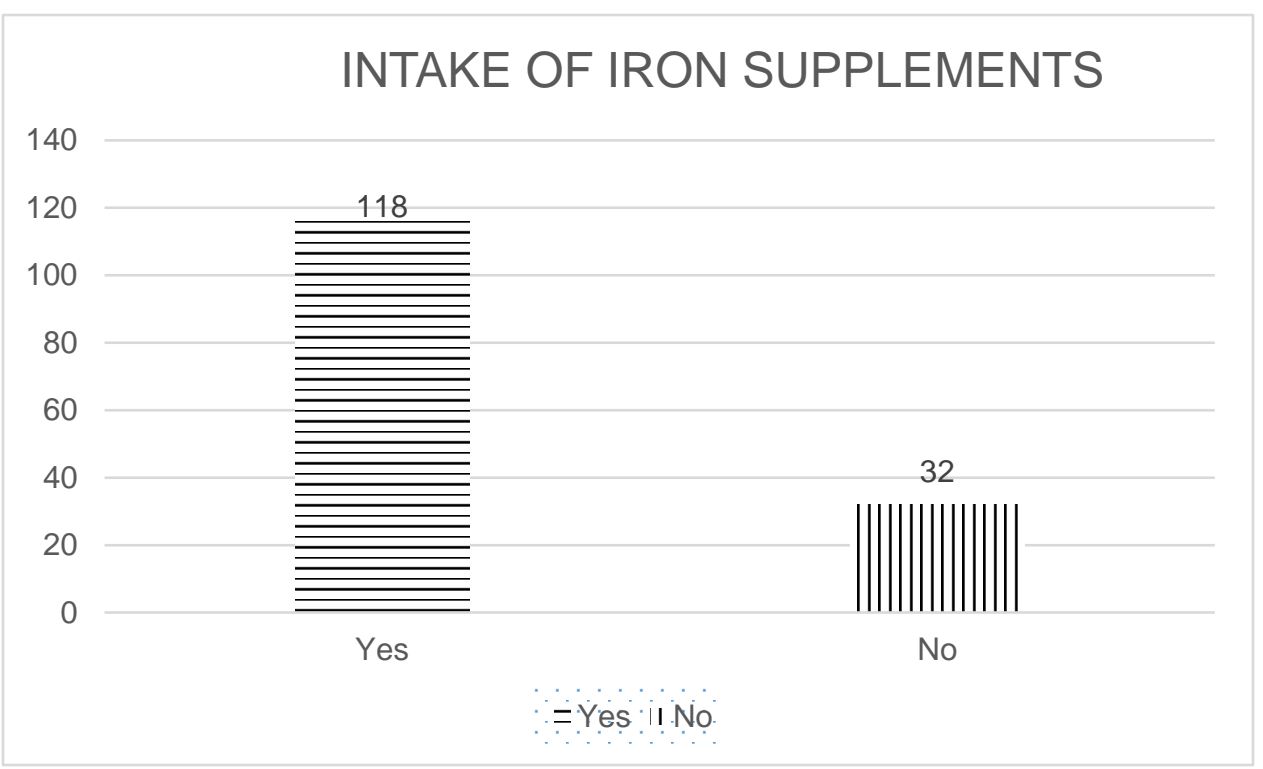

Figure 2: Frequency distribution of iron supplement intake

Frequency distribution of tea taken after meals 


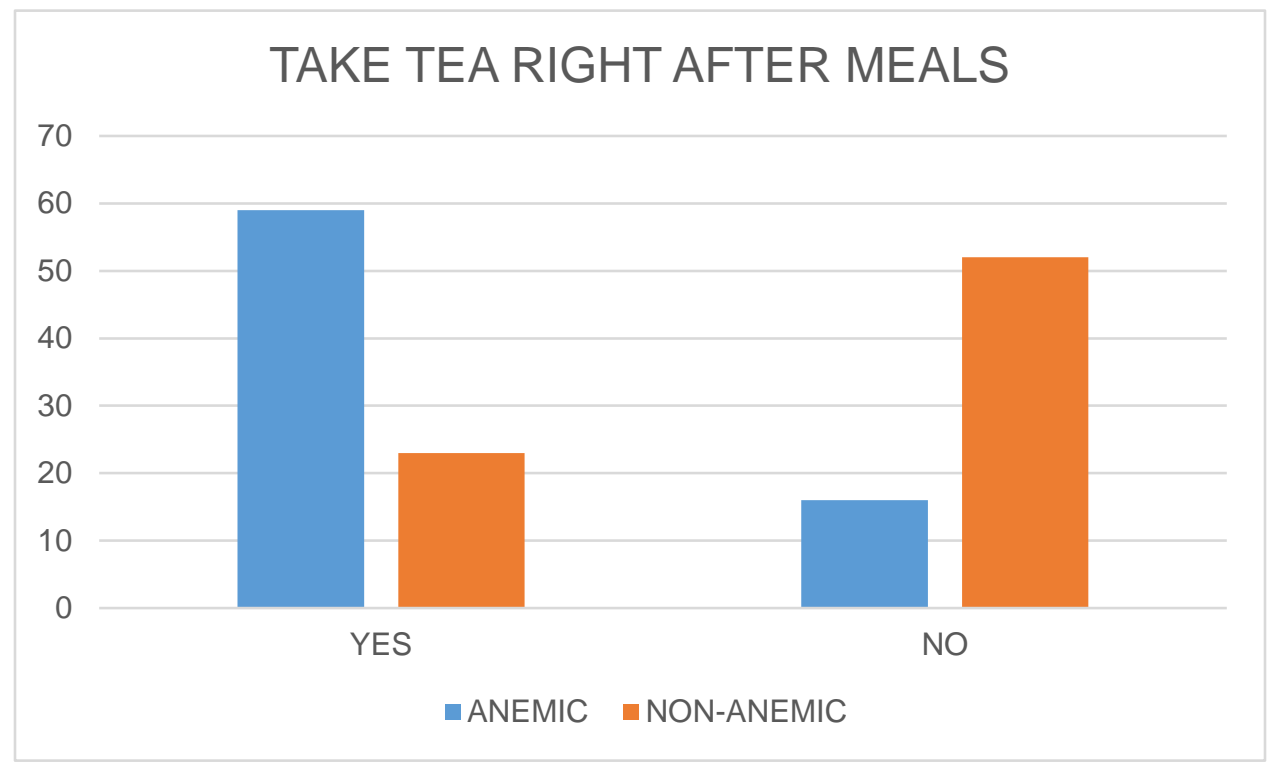

Figure 3: Association between taking tea right after meals and Anemia

\section{DISCUSSION}

The current study was aimed to assess dietary practices in pregnant women, by comparison among anemic and non-anemic females. Analysis revealed that anemia was more persistent in the third trimester of pregnancy and similar results were found in previous studies by Ergöçmen BA et al; Amany Mukhtar and colleague [20].

This research has found that anemic females have significantly higher (two and more than two times a day) daily consumption of tea and coffee and the majority of them took one of their tea serving with the breakfast meal. Likewise, results were reported in previous studies that tannins interfere with the absorption of non-haem iron in the body and become a major causative factor.

According to the current results, $34 \%$ of pregnant anemic women had pica cravings. $18 \%$ of women craved raw rice, $8 \%$ craved mud, $7.3 \%$ craved for ice and $0.7 \%$ craved for other non-food substances. Roy A et al; noted similar results in his research study from which he inferred that $37.6 \%$ of women were occupied with pica suggesting a strong association between anemia and pica [21].

\section{CONCLUSIONS}

Based on the results of the current study, second and third trimester of pregnancy, multigravida, pica, lower socio-economic status, feeling fatigued, shortness of breath, nausea, spoon-shaped nails, bones pain, joints pain, less physical activity, loss of appetite, tea consumption right after meals, food insecurity, vitamins and minerals deficiency, poor and low protein diet are among the significant risk factors for anemia. Lack of education, lower literacy rate, and no knowledge of balanced diet, improper and infrequent supplementation also contributed to a higher prevalence of anemia in pregnancy. If anemia remained undiagnosed and untreated, it may lead to many complications including miscarriages, stillbirths, mental health impairment in child and low birth weight.

\section{REFERENCES}

1. Jans $\varnothing$, Nielsen CS, Khan N, Gromov K, Troelsen A, Husted H. Iron deficiency and preoperative anaemia in patients scheduled for elective hip-and knee arthroplasty-an observational study. Voxsanguinis. 2018;113(3):2607.doi.org/10.1111/vox.12630.

2. Stevens GA, Finucane MM, De-Regil LM, et al. Global, regional, and national trends in haemoglobin concentration and prevalence of total and severe anaemia in children and pregnant and non-pregnant women for 1995-2011: a systematic analysis of population-representative data. Lancet Glob Health. 2013;1(1):e16-e25. doi:10.1016/S2214109X(13)70001-9 
3. Lanier JB, Park JJ, Callahan RC. Anemia in older adults. American family physician. 2018;98(7):437-42. doi.org/10.1371/journal.pntd.0008466.

4. Cases A,Egocheaga MI, Tranche S, Pallarés V, Ojeda R, Górriz JL, Portolés JM. Anemia of chronic kidney disease: Protocol of study, management and referral to Nephrology. Nefrología (English Edition). 2018;38(1):8-12. doi.org/10.1016/j.nefroe.2018.01.007.

5. Phillips J, Henderson AC. Hemolytic anemia: evaluation and differential diagnosis. American family physician. 2018;98(6):354-61. https://www.aafp.org/afp/2018/0915/p354.html.

6. Kather S, Grützner N, Kook PH, Dengler F, Heilmann RM. Review of cobalamin status and disorders of cobalamin metabolism in dogs. Journal of veterinary internal medicine. 2020;34(1):13-28.doi.org/10.1111/jvim.15638.

7. Anaemia in low-income and middle-income countries - PubMed. Accessed June 3, 2021. https://pubmed.ncbi.nlm.nih.gov/21813172/

8. Mohammed SH, Larijani B, Esmaillzadeh A. Concurrent anemia and stunting in young children: prevalence, dietary and non-dietary associated factors. Nutrition journal. 2019;18(1):1-0. doi.org/10.1017/jns.2021.75

9. Lone NM, Shah SH, Farooq M, Arif M, Younis S, Riaz S. Role of TMPRSS6 rs855791 (T> C) polymorphism in reproductive age women with iron deficiency anemia from Lahore, Pakistan. Saudi journal of biological sciences. 2021;28(1):748-53.doi.org/10.1016/j.sjbs.2020.11.004.

10. Busti F, Campostrini N, Martinelli N, Girelli D. Iron deficiency in the elderly population, revisited in the hepcidin era. Front Pharmacol. 2014;5:83. doi:10.3389/fphar.2014.00083

11. Long-Lasting Neural and Behavioral Effects of Iron Deficiency in Infancy. Accessed June 3, 2021. https://www.ncbi.nlm.nih.gov/pmc/articles/PMC1540447/

12. Leung AK, Hon KL. Pica: a common condition that is commonly missed-an update review. Current pediatric reviews. 2019;15(3):164-9.doi.org/10.2174/1573396315666190313163530.

13. Maternal iron status and neonatal outcomes in women with pica during pregnancy - PubMed. Accessed June 3, 2021. https://pubmed.ncbi.nlm.nih.gov/17572424/.

14. Delil R, Tamiru D, Zinab B. Dietary diversity and its association with anemia among pregnant women attending public health facilities in south Ethiopia. Ethiopian journal of health sciences. 2018;28(5). doi.org/10.4314/ejhs.v28i5.14.

15. Sifakis S, Pharmakides G. Anemia in Pregnancy. Ann N Y Acad Sci. 2000;900:125-136. doi:10.1111/j.17496632.2000.tb06223.x.

16. Skolmowska D, Głąbska D. Analysis of heme and non-heme iron intake and iron dietary sources in adolescent menstruating females in a national polish sample. Nutrients. 2019;11(5):1049.doi.org/10.3390/nu11051049.

17. (PDF) Prevalence of Anemia and Associated Risk Factors among Pregnant Women Attending Antenatal Care in Azezo Health Center Gondar Town, Northwest Ethiopia. Accessed June 3, 2021. https://www.researchgate.net/publication/273562888_Prevalence_of_Anemia_and_Associated_Risk_Factors_among _Pregnant_Women_Attending_Antenatal_Care_in_Azezo_Health_Center_Gondar_Town_Northwest_Ethiopia.

18. Pakistan National Nutrition Survey 2011.pdf. Accessed June - 3, 2021. https://www.mhinnovation.net/sites/default/files/downloads/innovation/research/Pakistan\%20National\%20Nutrition \%20Survey\%202011.pdf

19. Lee G, Choi S, Kim K, Yun JM, Son JS, Jeong SM, Kim SM, Park SM. Association of hemoglobin concentration and its change with cardiovascular and all-cause mortality. Journal of the American Heart Association. 2018 ;7(3):e007723.doi.org/10.1161/JAHA.117.007723.

20. Prevalence and Risk Factors of Anemia among a Sample of Pregnant Females AttendingPrimary Health Care Centers in Makkah, Saudi Arabia. doi:10.3923/pjn.2012.1113.1120.

21. Roy A, Fuentes-Afflick E, Fernald LCH, Young SL. Pica is prevalent and strongly associated with iron deficiency among Hispanic pregnant women living in the United States. Appetite. 2018;120:163-170. doi:10.1016/j.appet.2017.08.033. 